\title{
Avaliação do perfil farmacognóstico e do potencial antimicrobiano do extrato etanólico do caule da Cecropia pachystachya T. (embaúba)
}

\author{
Evaluation of pharmacognostic profile and antimicrobial potential of \\ the ethanolic extract of Cecropia pachystachya T. (embaúba)
}

Recebido em: 03/04/2018 Aceito em: 22/06/2018
Alvelino Serafim MESQUITA' ${ }^{1}$; Paulo Augusto Oliveira VENTURA ${ }^{1}$;

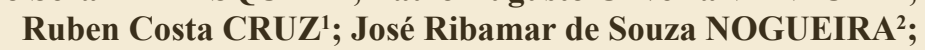
Alvaro Carlos GALDOS-RIVEROS ${ }^{3}$ ${ }^{1}$ Faculdade Anhanguera de Brasilia. QS 1, rua 212, lotes 11,13 e 15, Águas Claras. Brasilia, DF, Brasil. ${ }^{2}$ Universidade Católica de Brasília, Campus I. QS 07, Lote 01, EPCT, Águas Claras. Brasília, DF, Brasil.

${ }^{3}$ Faculdade de Sinop - FASIPE. Av. Magda Cassia Pissinati, 69, Residencial Florença.Sinop, MT, Brasil.E-mail: alvarogaldos@usp.br

\section{ABSTRACT}

Many of the plants found in the Brazilian savanna are used for the treatment of numerous diseases. These plants present several peculiarities, such as the family Cecropiaceae. One of them, Cecropia pachystachya, known as embaúba, features popular indications in the treatment of asthma, coughs, cardiovascular problems and diabetes. The present study aimed to evaluate the phytochemical profile of ethanol extract of the stem of Cecropia pachystachya and the antimicrobial potential of stem extracts with 07 15, 30, and 45 days of maceration. According to the tests, the presence of tannins and flavonoids in all extracts was confirmed. In the analysis, the ethanol extract of 7 and 45 days of maceration presented halo of inhibition for Staphylococcus aureus. It was concluded that the stem of the Cecropia pachystachya presented flavonoids and tannins, possibly the responsible of the antimicrobial effect in Staphylococcus aureus.

Keywords: Mirmecophyta, phytotherapy, Staphylococcus aureus, bioactive compounds, Cecropia pachystachya.

\section{RESUMO:}

Muitas das plantas encontradas na savana brasileira são utilizadas, pela população, no tratamento de inúmeras doenças, apresentando muitas peculiaridades, por exemplo, plantas da família Cecropiaceae. A Cecropia pachystachya, conhecida popularmente por embaúba, apresenta indicações populares no tratamento de asma, tosse, problemas cardiovasculares e diabetes. O presente trabalho teve como objetivo avaliar o perfil fitoquímico do extrato etanólico do caule da Cecropia pachystachya e o potencial antimicrobiano do extrato do caule com 07, 15, 30 e 45 dias de maceração. De acordo com os testes, foi confirmada a presença de taninos e flavonoides em todos os extratos. Na análise antimicrobiana, os extratos etanólicos de 7 e 45 dias de maceração apresentaram halo de inibição em relação à Staphylococcus aureus. Dessa forma, o caule da Cecropia pachystachya apresentou um perfil farmacognóstico composto por flavonoides e taninos, sendo possivelmente atribuído a esses o efeito antimicrobiano frente a Staphylococcus aureus.

Palavras-Chave: mirmecófita; fitoterapia; Staphylococus aureus; compostos bioativos, Cecropia pachystachya. 


\section{INTRODUÇÃO}

O Brasil abriga cerca de $10 \%$ das formas viventes no planeta, portanto é um dos países de maior diversidade biológica (1). Apresenta seis tipos de biomas: Amazônia, Caatinga, Mata Atlântica, Pampa, Pantanal e o Cerrado (2).

O bioma Cerrado é um complexo vegetacional caracterizado pela savana tropical, com formações herbáceas, florestais, arbustivas, arbóreas e campestres (3). Entre elas pode ser citada a família Cecropiaceae, composta por 75 espécies, das quais destaca-se o gênero Cecropia (4). As espécies desse gênero são empregadas, pela população, no tratamento de tosse (5), asma e bronquite (6), pressão alta (7), diabetes (8), inflamações (9), e como diuréticas e cardiotônicas (10).

Cecropia pachystachya é uma planta mirmecófita, assim denominada por interagir com colônias de formigas (11) que geralmente se abrigam em estruturas chamadas de domáceas (12). Possui folhas grandes e lobadas (13), é frutífera, fornecendo alimento para morcegos e várias espécies de pássaros.

Nas folhas desse vegetal foram identificados constituintes químicos como flavonoides e taninos, apontados como compostos farmacognósticos responsáveis pelo alto potencial antioxidante da planta (14), comprovado pelo método do caroteno (15).

Costa e cols. (2011), em um estudo farmacognóstico utilizando duas espécies de Cecropia, dentre elas $C$. pachystachya, conseguiu identificar, no extrato aquoso das folhas, cinco compostos fenólicos (ácido clorogênico, isoquercitrina, orientina, isoorientina e isovitexina), dos quais os três últimos foram isolados (16). De acordo com Lucon Junior (2013), algumas destas moléculas bioativas conferem atividade antimicrobiana à espécie, como observado em experimento no qual, a partir de uma concentração de $2,5 \mathrm{mg} / \mathrm{mL}$ de extrato da planta, houve a inibição da bactéria Staphylococcus aureus (27).

A resistência a antibióticos tem crescido e constitui problema que alcança a população de maneira generalizada, chamando a atenção de profissionais de distintas áreas, e gera grande número de mortalidade por infecções, maior dispêndio no tratamento e desafio ao manejo clínico (17). A utilização equivocada de medicamentos com ação antimicrobiana é apontada como uma das causas mais importantes para o aparecimento de microrganismos resistentes (18), que são aqueles capazes de crescer junto a um ou mais antimicrobianos que possivelmente impediriam seu crescimento (19).
O uso de extratos obtidos a partir de plantas medicinais destinados ao combate a microrganismos patogênicos pode ser uma alternativa importante, haja vista a dificuldade que as bactérias possuem em tornar-se resistentes aos extratos, porquanto estes são constituídos de misturas complexas que atrapalham a adaptação do microrganismo (20). Logo, a presente pesquisa avaliou a possível atividade antimicrobiana de extratos etanólicos do caule da Cecropia pachystachya, obtidos após 7, 15, 30 e 45 dias de maceração, nas bactérias de interesse médico Staphylococcus aureus, Salmonella typhimurium e Escherichia coli, bem como avaliou o perfil farmacognósticos do extrato da planta.

\section{MATERIAL E MÉTODOS}

Droga vegetal. Foi utilizado o caule da Cecropia pachystachya colhido no Cerrado (Figura 1), nos arredores da rodovia GO-547, perímetro de Santo Antônio do Descoberto, Goiás, latitude $15^{\circ} 51$ '18.4"S e longitude $48^{\circ} 19^{\prime} 32.2^{\prime \prime} \mathrm{W}$. A planta foi devidamente identificada pelo biólogo José Ribamar de Souza Nogueira e uma exsicata foi depositada no Herbário da Faculdade Anhanguera de Brasília (voucher $n^{\circ} 27.1002$ ). A amostra utilizada na obtenção do extrato após 15,30 e 45 dias foi coletada em estação chuvosa no mês de fevereiro de 2015 e a amostra obtida para extração do extrato de 7 dias foi coletada na estação seca, no mês de julho de 2015, de forma ser possível analisar as possíveis alterações em compostos secundários devido às características climáticas de cada época de colheita. Colhida a droga vegetal, esta foi submetida à desidratação em estufa pelo período de 24 horas, sob temperatura de $35^{\circ} \mathrm{C} \pm 2^{\circ} \mathrm{C}$.

Extrato Etanólico. A obtenção dos extratos de 7, 15,30 e 45 dias seguiu a metodologia de Nascimento (2012) (21), com adaptações. Uma amostra de $40 \mathrm{~g}$ do caule triturado foi diluído em $450 \mathrm{~mL}$ de álcool etílico absoluto (99,5\%), deixando em maceração por 7, 15, 30 e 45 dias e sob agitação diária durante 30 minutos com agitador magnético. O recipiente foi revestido com papel alumínio, protegendo a amostra da luz visível. No decorrer do processo de extração, os extratos foram acondicionados sob temperatura de 2 a $8^{\circ} \mathrm{C}$ para conservação.

Decorridos 7, 15, 30 e 45 dias de maceração, os extratos foram filtrados e submetidos a rotaevaporador (Fisatom, modelo 801), com rotação de $40 \mathrm{rpm}$, na temperatura de $92-96^{\circ} \mathrm{C}$, retirando-se o solvente com consequente concentração do extrato.

O rendimento dos extratos foi obtido pela razão entre o peso em gramas do extrato e o peso em gramas 
da droga vegetal, multiplicando-se o valor final por 100 (22).

Prospecção farmacognóstica qualitativa. Os extratos foram submetidos à análise fitoquímica qualitativa em duplicata de acordo com a metodologia adaptada de Costa (2002) (23) e Simões e cols. (2010) (24), por meio da adição de reagentes específicos que desencadearam alterações de cor e formação de precipitados, na busca de possível presença de alcaloides, flavonoides, terpenos, glicosídeos, taninos, antraquinonas e saponinas.
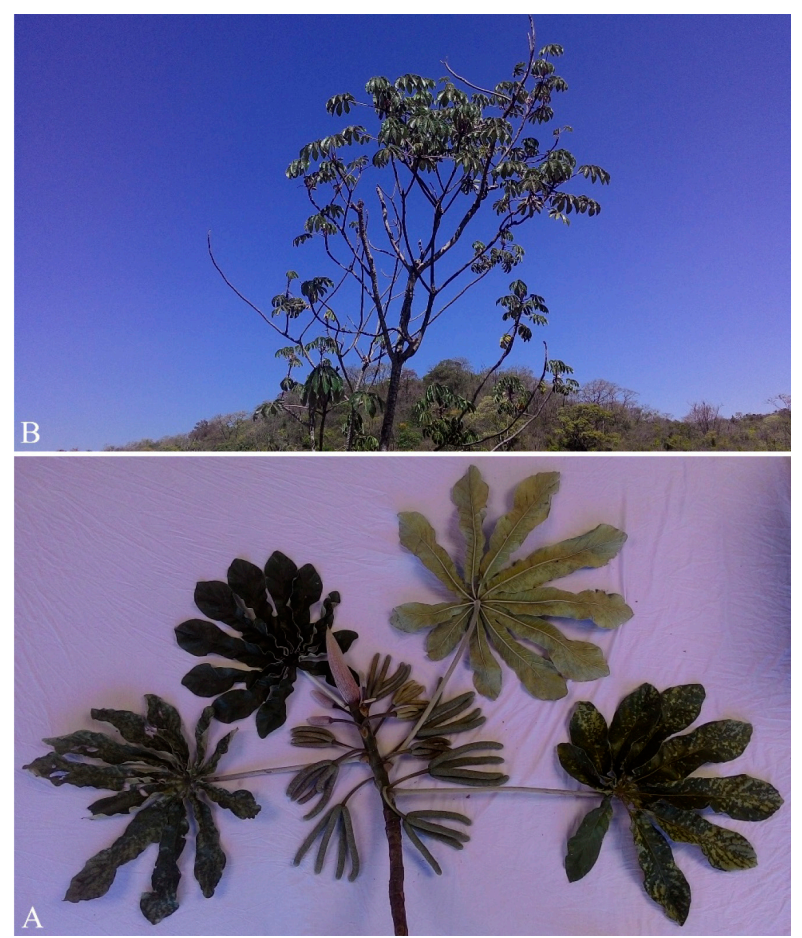

Figura 1. Cecropia pachystachya. (A) Planta no seu habitat natural, nos arredores da rodovia G0-547, perímetro de Santo Antônio do Descoberto, Goiás; (B) detalhe das folhas e das inflorescência.

Potencial antimicrobiano. A avaliação da atividade antibacteriana foi realizada em duplicata por testes in vitro. Foram utilizadas as cepas liofilizadas padrão (American Type Culture Colletion) de Staphylococcus aureus, ATCC 25923 (LABORCLIN), Salmonella typhimurium ATCC 123912 (LABORCLIN) e Escherichia coli ATCC 35218 (LABORCLIN). Em um primeiro momento, foi preparada a cepa concentrada de cada uma das bactérias utilizadas. Para revitalização das cepas foi utilizado caldo de Brain Heart Infusion (BHI). Foram pesados 2,2 $\mathrm{g}$ do pó de $\mathrm{BHI}$ e dissolvidos em $60 \mathrm{~mL}$ de água destilada esterilizada, homogeneizando a solução com auxílio de agitador magnético. Em cada um dos frascos contendo a respectiva cepa bacteriana liofilizada foi adicionado 1 $\mathrm{mL}$ do caldo de BHI. Os frascos foram homogeneizados e $50 \mu \mathrm{L}$ da solução foram transferidos separadamente para 3 tubos de ensaio com tampa rosqueável contendo $5 \mathrm{~mL}$ da solução de BHI. Nova homogeneização foi realizada manualmente. Após, $100 \mu \mathrm{L}$ da solução bacteriana foram pipetados separadamente em outros 3 tubos de ensaio com tampa rosqueável contendo $5 \mathrm{~mL}$ de caldo BHI, levando-se para a estufa bacteriológica (Quimis, Q-316B3) a $35^{\circ} \mathrm{C} \pm 2^{\circ} \mathrm{C}$, por 24 horas. Após o período de incubação, foi obtida a cepa concentrada.

A partir das cepas concentradas foram preparadas as cepas de trabalho. A cepa concentrada foi diluída até turvação equivalente ao tubo 0,5 da escala McFarland, que corresponde a $1,5 \times 10^{8} \mathrm{UFC} / \mathrm{mL}$. A técnica, adaptada de Bauer e cols. (1966) (25), foi utilizada, esterilizando-se, por autoclavação, 5 tubos contendo $9 \mathrm{~mL}$ de solução salina $0,9 \%$. Nesses tubos, $100 \mu \mathrm{L}$ de cada cepa concentrada foram pipetados separadamente. Em espectrofotômetro (Químis, Q-108 DP), com absorbância ajustada em $625 \mathrm{~nm}$, foi feita a leitura dos tubos, cuja absorbância estabilizou-se entre 0,08 e $0,1 \mathrm{~nm}$, o que equivale à concentração da cepa contida no tubo 0,5 da escala McFarland, obtendo-se a cepa de trabalho.

Da cepa de trabalho, $100 \mu \mathrm{L}$ foram pipetados em placas de Petri com o meio de cultura ágar Mueller-Hinton (Biomerieux, lote 1408110706). Pela técnica de esgotamento, com auxílio de Swab estéril (LaborSwab lote 020806A), cada cultura foi estriada uniformemente por toda superfície de sua respectiva placa. Em seguida, poços de $6 \mathrm{~mm}$ foram perfurados no meio de cultura utilizando-se pipetas estéreis, nos quais pipetou-se $100 \mu \mathrm{L}$ das diluições do extrato que foram realizadas com água destilada nas proporções 1:1, 1:2, 1:4, 1:8, 1:16, 1:32, $1: 64,1: 128,1: 256,1: 512,1: 1024,1: 2048$ e 1:4096. Todos os testes foram realizados em duplicata. Concluída a pipetagem dos extratos nos poços, as placas foram mantidaas em estufa bacteriológica (Quimis) à $35^{\circ} \mathrm{C} \pm 2^{\circ} \mathrm{C}$, por um período de 24 horas, de acordo com metodologia de Nascimento e cols. (2000) (26). Por meio de paquímetro manual foram medidos os halos formados logo após o período de 24 horas.

Amoxicilina $10 \mu \mathrm{g}$ (LABORCLIN, lote: 30125053) foi utilizada como controle positivo do experimento por ter apresentado melhores resultados em teste prévio de sensibilidade antimicrobiana em cada cepa. Como controle negativo utilizou-se água destilada esterilizada. 


\section{RESULTADOS E DISCUSSÃO}

Rendimento dos extratos. A Tabela 1 mostra o rendimento dos extratos obtidos por diferentes períodos de maceração

Tabela 1. Rendimento dos extratos etanólicos do caule de Cecropia pachystachya.

\begin{tabular}{|c|c|}
\hline Extrato por tempo de maceração & Rendimento (\%) \\
\hline 7 dias & 13,5 \\
\hline 15 dias & 12,3 \\
\hline 30 dias & 11,8 \\
\hline 45 dias & 11,2 \\
\hline
\end{tabular}

Em seus experimentos, Lucon Junior (2013) comparou os rendimentos de extrato à base de acetona e água (7:3) com extrato à base de etanol absoluto das folhas de Cecropia pachystachya, concluindo que os extratos à base de etanol apresentavam maior rendimento de massa extrativa, assim como menor custo e baixa toxicidade (27).

Silva e cols. (2017), em experimentos com folhas de Croton urucurana Baillon, obtiveram rendimento de $14 \%$ utilizando o solvente etanol, resultado superior quando comparado ao extrato aquoso da planta, que chegou a $10 \%$, confirmando, em outras espécies de plantas, que o solvente etanol é eficiente em relação ao rendimento da extração (28).

Alves e cols. (2017), na extração utilizando folhas de Morus alba L., registraram rendimento de 11,5\% quando utilizaram etanol como solvente e $22,5 \%$ quando utilizaram solução hidroalcoólica, demonstrando também a efetividade do solvente hidroalcoólico em processos extrativos (29).

Análise farmacognóstica qualitativa. Finalizada a análise, foi confirmada a presença de flavonoides e taninos, porém, saponinas, terpenos, antraquinonas, glicosídeos e alcaloides não foram detectados nos extratos. Os resultados corroboram os estudos realizados por Silva e cols (2013), que demonstraram a presença de flavonoides e taninos em Cecropia pachystachya (30). Experimentos conduzidos por Costa e cols. (2011) apontaram que o extrato aquoso das folhas da espécie analisada continham os flavonoides isoquercitrina, orientina, isoorientina e isovitexina, como também ácido clorogênico (16). Nos testes quantitativos por Cromatografia Líquida de Alta Eficiência com detector de matriz fotodiodo (CLAE-DAD), isoorientina foi identificada como a molécula de maior abundância em C. pachystachya. Souza e cols. (2014) constataram que o extrato etanólico obtido da casca de C. pachystachya continha catequinas, taninos, leucoantocianidinas, xantonas, auronas, chalconas, flavonas, flavonois e flavanonois (31). Esses mesmos autores identificaram, em uma fração metanólica do extrato etanólico, taninos pirogálicos e flavononas.

Conforme Zuanazzi e cols. (2010), o emprego de plantas que possuem flavonoides visando o tratamento de doenças é amplo e ainda empírico em muitas ocasiões. Citam que determinados medicamentos produzidos à base de flavonoides são empregados no tratamento de distúrbios circulatórios, hipertensão, e também como cofator da vitamina C (32). De acordo com os autores, determinados flavonoides desencadeiam ação antitumoral a atuam como antivirais, anti-hemorrágicos, hormonais, anti-inflamatórios, antioxidantes e antimicrobianos.

$\mathrm{O}$ efeito antimicrobiano dos flavonoides tem sido atribuído às flavonas, chalconas e à quercetina $(33,34)$; e flavonas e chalconas foram detectadas em C. pachystachya.

Vários estados patológicos como diarreia, hipertensão arterial, inflamações, distúrbios renais, úlceras gástricas, gastrite, náuseas e azia, reumatismo, feridas e queimaduras são tratados na medicina tradicional utilizando-se plantas taníferas (35-37). A atividade inibitória de fungos e bactérias por taninos foi apresentada ao meio científico, dentre outros, por meio de estudos realizados por Scalbert (1991) (38) e Waage e cols. (1984) (39).

Em toda literatura consultada não houve registros sobre a presença de saponinas, antraquinonas, alcaloides, terpenos e glicosídeos na espécie estudada, igualmente aos resultados encontrados nesta pesquisa. 
Tabela 2. Diluições do extrato etanólico de 7 dias e de 45 dias de maceração da Cecropia pachystachya apresentando concentrações $(\mathrm{mg} / \mu \mathrm{L})$ e zona de inibição $(\mathrm{mm})$ referente a Staphylococcus aureus.

\begin{tabular}{|c|c|c|}
\hline \multicolumn{3}{|c|}{ Extrato de 7 dias } \\
\hline $\begin{array}{l}\text { Título das } \\
\text { diluiçõ̂es }\end{array}$ & $\mathrm{mg} / 100 \mu \mathrm{L}$ & halo (mm) \\
\hline $1: 1$ & 108 & 24,1 \\
\hline $1: 2$ & 54 & 23,6 \\
\hline $1: 4$ & 27 & 23,3 \\
\hline $1: 8$ & 13,5 & 20,2 \\
\hline $1: 16$ & 6,8 & 20,7 \\
\hline $1: 32$ & 3,4 & 17,8 \\
\hline 1:64 & 1,7 & 16,6 \\
\hline 1:128 & 0,8 & 15,2 \\
\hline $1: 256$ & 0,4 & 13,4 \\
\hline 1:512 & 0,2 & 12,9 \\
\hline 1:1024 & 0,1 & 9,8 \\
\hline $1: 2048$ & $5 \times 10^{2}$ & - \\
\hline $1: 4096$ & $2,3 \times 10^{2}$ & - \\
\hline \multicolumn{3}{|c|}{ Extrato de 45 dias } \\
\hline $\begin{array}{l}\text { Título das } \\
\text { diluiçōes }\end{array}$ & $\mathrm{mg} / 100 \mu \mathrm{L}$ & halo (mm) \\
\hline $1: 1$ & 89 & $1,2 \mathrm{~mm}$ \\
\hline
\end{tabular}

De acordo com a Tabela 2, tanto os extratos submetidos à maceração por menor período (7 e 15 dias) como os submetidos à maceração por maior período $(30$ e 45 dias) apresentaram perfil farmacognóstico positivo para flavonoides e taninos. Não houve alteração na presença dos compostos extraídos a partir dos caules coletados em época chuvosa e dos caules coletados em época de estiagem; entretanto não é descartada a possibilidade de alteração na concentração dessas moléculas em razão das condições climáticas no momento da coleta. Testes quantitativos podem ser utilizados para relacionar suas concentrações em extratos com tempo de maceração distintos, assim como em épocas distintas da colheita da amostra vegetal.

Análise antimicrobiana. As análises in vitro mostraram que os extratos obtidos em 7 e 45 dias de maceração apresentaram halo de inibição em relação a Staphy- lococcus aureus (Tabela 2); entretanto, o halo referente ao extrato de 45 dias de maceração não foi considerado como indicativo de possível atividade antimicrobiana. Os extratos obtidos em 15 e 30 dias de maceração não mostraram atividade antimicrobiana, porquanto não houve formação de halo de inibição. Foi observado, ainda, que nenhum dos extratos conseguiu inibir as bactérias Escherichia coli e Salmonella. typhimurium. A Tabela 3 mostra os halos de inibição dos controles utilizados nos experimentos.

Tabela 3. Zona de inibição dos controles utilizados no experimento.

\begin{tabular}{|c|c|c|}
\multirow{2}{*}{ microrganismo } & \multicolumn{2}{|c|}{ controles } \\
\cline { 2 - 3 } & amoxicilina & água destilada \\
\hline Staphylococcus aureus & $23 \mathrm{~mm}$ & - \\
\hline Escherichia coli & $20 \mathrm{~mm}$ & - \\
\hline Salmonella sp. & $21 \mathrm{~mm}$ & - \\
\hline
\end{tabular}

(-): ausência de inibição.

De acordo com trabalho realizado por Lucon Junior (2013), o extrato etanólico de Cecropia pachystachya apresentou atividade bactericida, com concentração inibitória mínima (CIM) de $2,5 \mathrm{mg} / \mathrm{mL}$, frente à cepa Staphylococcus aureus isolada de mastite bovina, como também à cepa S. aureus ATCC 29231 (27). Souza e cols. (2014), em estudo utilizando o extrato e as frações metanólicas de Cecropia pachystachya, constataram que os extratos e frações, de forma isolada, não apresentaram ação antimicrobiana em S. aureus; no entanto, em associação à aminoglicosídeos, por método de microdiluição, foi observado sinergismo do extrato com o antimicrobiano, haja vista a redução da concentração inibitória mínima desse último (31). Taguri e cols. (2004) atribuíram aos taninos e flavonoides a capacidade de melhorar a absorção de fármacos por bactérias, haja vista a habilidade daqueles em alterar a parede celular ou até mesmo destruir a membrana plasmática deste tipo de microrganismo, favorecendo o sinergismo entre o antimicrobiano e o produto natural (40). Paula (2010), pelo método de difusão em disco, registrou a formação de halos de inibição de 10 mm e $12 \mathrm{~mm}$ mediante teste utilizando extrato metanólico de Cecropia pachystachya em Staphylococcus aureus, configurando atividade antimicrobiana (41). Pesquisas conduzidas por Sousa e cols. (2015) mostraram que o extrato etanólico de Cecropia pachystachya apresentou efeito inibitório nas diluições 1:1, 1:2 e 1:4, formando 
halos de inibição de 16,1 mm, 13,4 mm e 13,8 mm, respectivamente, frente à Staphylococcus aureus (42). No mesmo estudo foi observado que o extrato aquoso da planta inibiu Staphylococcus aureus na concentração 1:1, formando halo de inibição de $9,0 \mathrm{~mm}$.

Os extratos de plantas, por terem uma composição molecular complexa, dificultam a formação de mecanismos de resistência por parte dos microrganismos como bactérias de interesse médico (43). Dentre essas moléculas, a literatura científica cita os taninos e flavonoides como responsáveis pela atividade antimicrobiana de plantas (44). Os taninos, segundo Schofield e cols. (2001), atuam em bactérias influenciando negativamente seu crescimento por meio da interferência na fosforilação oxidativa e pela inibição de enzimas extracelulares, o que pode justificar sua ação antibacteriana (45).

Em relação aos flavonoides, estudos tem demonstrado que algumas características estruturais dessa classe fitoquímica promovem maior inibição das funções da membrana celular de bactérias $(46,47)$, e que flavonoides hidroxilados no anel B são responsáveis pela inibição de ácidos nucleicos bacterianos, atestando atividade antimicrobiana (48).

Levando-se em consideração a presença dessas duas classes farmacognósticas nos extratos testados, há possibilidade de que a atividade antimicrobiana da planta seja devida a estes compostos. Observando a Tabela 2, pode ser constatado que o extrato obtido após 7 dias de maceração conseguiu formar halos de inibição com maiores diâmetros que o extrato de 45 dias de inibição.

Os metabólitos secundários funcionam como mediadores químicos entre as plantas e o meio ambiente, o que ocasiona alterações perceptíveis na síntese desses metabólitos quando há mudanças ambientais (49).

Um dos fatores de maior importância em relação à coleta de plantas é justamente a época, levando em consideração que tanto a quantidade como o tipo de me- tabólitos não é igual no decorrer do ano (50). Variações sazonais que levam a alterações no conteúdo de constituintes fitoquímicos são citadas para praticamente todas as classes de metabólitos, a exemplo, os flavonoides (51) e taninos $(52,53)$.

A disponibilidade hídrica é um dos fatores que influenciam a quantidade de metabólitos secundários nas plantas; entretanto, em relação a compostos fenólicos, a literatura científica apresenta registros conflitantes, dificultando a comparação objetiva entre a concentração dessas substâncias e a quantidade de água da planta $(54,55)$. Entretanto, estudos apontam que a chuva prolongada pode desencadear perda de substâncias hidrossolúveis de folhas e raízes por lixiviação (56).

A seca, em alguns casos, interfere na concentração de metabólitos, mas, para isso, há de se observar o grau de estresse e o período em que ocorre, porquanto há indícios de que períodos curtos de seca levam ao aumento do conteúdo de metabólitos, e períodos maiores parecem reduzir o conteúdo de metabólitos (57).

Portanto, a diferença entre os halos obtidos utilizando-se o extrato de 7 dias e o extrato de 45 dias pode ser devida à diferença entre as épocas de coleta das amostras vegetais, à disponibilidade hídrica, como também aos demais fatores ambientais aos quais estavam sujeitas as amostras. $\mathrm{O}$ tempo de maceração pode também ter influenciado no resultado dos testes.

\section{CONCLUSÃO}

Com base nos resultados obtidos, o caule da Cecropia pachystachya apresentou um perfil fitoquímico composto por flavonoides e taninos. A presença destes possivelmente possibilitou o efeito antimicrobiano frente a Staphylococcus aureus. O caule mostrou ser uma fonte importante na procura de um novo fitoterápico, haja vista a capacidade antimicrobiana demonstrada.

\section{REFERÊNCIAS}

1. Myers N, Mittermeier RA, Mittermeier CG, Fonseca GAB, Kent J. Biodiversity hotspots for conservation priorities. Nature. 2000; 403:853-858. DOI: 10.1038/35002501.

2. BRASIL. Instituto Brasileiro de Geografia e Estatística (IBGE). Mapa de Biomas do Brasil. Escala 1:5.000. Rio de Janeiro (RJ); 2004; Disponível em: http://mapas.ibge. gov.br/biomas2/viewer.htm.
3. BRASIL. Empresa Brasileira de Pesquisa Agropecuária (EMBRAPA). Mapeamento de Cobertura Vegetal do Bioma Cerrado. $1^{\mathrm{a} e d}$. Brasília (DF); 2008. Disponível em: http:ainfo.cnptia.embrapa.br/digital/bitstream/ item/76789/1/bolpd-205.pdf.

4. Tanae MM, Lima-Landman MT, De Lima TC, Souccar C, Lapa AJ. Chemical standardization of the aqueous extract of Cecropia glaziovii Sneth endowed with antihyperten- 
sive, bronchodilator, antiacid secretion and antidepressant-like activities. Phytomedicine, 2007;14(5):309-313. DOI: 10.1016/j.phymed.2007.03.002.

5. Pio Corrêa M. Dicionário das Plantas Úteis do Brasil e das Exóticas Cultivadas. v. 4. Rio de Janeiro: Imprensa Nacional. 1978.

6. Lorenzi H, Matos FJA. Plantas Medicinais no Brasil: Nativas e Exóticas. Nova Odessa: Instituto Plantarium de Estudos da Flora Ltda. 2008.

7. Mors WB, Rizzini CT, Pereira NA. Medicinal Plants of Brazil. Algonac: Reference Publications. 2000.

8. Carneiro JGA. Produção e controle de qualidade de mudas florestais. Curitiba: UFP. 1995.

9. Di Stasi LC, Seito LN, Huruma-Lima CA. Urticales medicinais in Plantas medicinais na Amazônia e na Mata Atlântica. São Paulo: UNESP. 2002.

10. Simões CMO, Mentz LA, Schenkel EP, Irgang BE, Stehmann JR. Plantas da medicina popular do Rio Grande do Sul. Porto Alegre: UFRGS. 1998.

11. Longino JT. Geographic variation and community structure in an ant-plant mutualism: Azteca and Cecropia in Costa Rica. Biotropica, 1989; 21: 126-132.

12. Lapola DM, Bruna EM, Vasconcelos HL. Mutualismo entre plantas e formigas na Amazônia. Ciência Hoje, Brasil, 2004;34(204):28-33.

13. Joly AB. Botânica: Introdução à taxonomia vegetal. Companhia Editora Nacional, São Paulo (SP); 1977. Disponível em: http://ecologia.ib.usp.br/curso/2008/pdf/I_GUILHERME.pdf.

14. Carvalho PS, Campos FA, Mendonça ED, Da Silva J, Ferraz A. Análise da constituição fitoquímica e antioxidante da embaúba (Cecropia pachystachya). In: XIX Salão de Iniciação Científica e Tecnológica. 2013. Canoas: ULBRA, 2013.

15. Simões VN, Minguzzi S. Estudo Fitoquímico e Testes Biológicos das Folhas da Cecropia pachystachya Trec. Anais do $7^{\circ}$ ENIC, 2011. 1(1). Disponível em: file:///C:/ Users/user/Desktop/1036-1560-1-PB.pdf.

16. Costa GM, Ortman CF, Schenkel EP, Reginatto FH. An HPLC-DAD Method to Quantification of Main Phenolic Compounds from Leaves of Cecropia Species. J. Braz. Chem. Soc. 2011;22(6): 1096-1102. DOI: dx.doi. org/10.1590/S0103-50532011000600014.

17. Matias EFF, Santos KKA, Almeida TS, Costa JGM, Coutinho HDM. Atividade antibacteriana in vitro de Croton campestris A., Ocimum gratissimum L. e Cordia verbenacea DC. Rev Bras Biociênc. 2010;8(3): 294-298.

18. Hamdan JS, Hahn RC. Antifungal drugs for systemic mycosis: an overview of mechanism of action and resistance. Antinfect Agents Med Chem. 2006;5(10): 403412. DOI: $10.2174 / 187152106778520479$.

19. Oliveira AC, Silva RS. Desafios do cuidar em saúde frente à resistência bacteriana: uma revisão. Rev Eletr Enf. 2008;10(1): 189-197.
20. Daferera DJ, Ziogas BN, Polissiou MG. The effectiveness of plant essential oils on the growth of Botrytis cinerea, Fusarium sp. and Clavibacter michiganesis subsp. michiganesis. Crop Prot. 2003;22(1): 39-44. DOI: 10.1016/S0261-2194(02)00095-9.

21. Nascimento L. Caracterização centesimal, composição química e atividade antioxidante do noni (Morinda citrifolia L.) cultivado no município de Zé Doca-MA [Dissertação]. Rio de Janeiro: Instituto de tecnologia, Universidade Federal Rural do Rio de Janeiro. 2012.

22. Almeida JCS, Rodrigues TS, Souza KF, Rodrigues-Das-Dores RG, Nagem TJ. Detecção de capsaicina em extratos dos frutos verdes e maduros de Capsicum baccatum L. pelas metodologías de cromatografía em camada delgada e histoquímica. Infarma Ciências Farmacêuticas. 2015;27(2):106-111. DOI: 10.14450/2318-9312.

23. Costa AF. Farmacognosia. 6. ed. Lisboa: Fundação Calouste Gulbenkian. 2002.

24. Simões CMO, Santos RI, Falkenberg MB. Introdução à análise fitoquímica. In: Simões CMO, Schenkel EP, Gosmann G, Mello JCP, Mentz LAl, Petrovick PR. Farmacognosia: da planta ao medicamento. $6^{\mathrm{a}}$ ed. Porto Alegre/ Florianópolis: editora da UFSC. 2010. p.229-246.

25. Bauer AW, Kirby WMM, Sherris JC, Turck M. Antibiotic susceptibility testing by a standardized single disk method. Am J Clin Pathol. 1966;45(4):493-496.

26. Nascimento GGF, Locatelli J, Freitas PC, Silva GL. Antibacterial activity of plant extracts and phytochemicals on antibiotic-resistant bacteria. Braz J Microbiol. 2000; 31(4):247-256. DOI: 10.1590/S151783822000000400003 .

27. Lucon Junior JF. Avaliação da atividade microbicida de extratos vegetais sobre Staphylococcus aureus isolados de mastite bovina. [Dissertação]. Ribeirão Preto: Faculdade e Zootecnia e Engenharia de Alimentos, Universidade de São Paulo. 2013.

28. Silva SCS, Alves MA, Sousa SA, Nogueira JRS, Martins, DHN, Fonseca-Bazzo YM, Galdos-Riveros AC. Perfil fitoquímico, susceptibilidade antibacteriana e capacidade antioxidante das folhas de Croton urucurana Baillon (Euphorbiaceae). Infarma - Ciências Farmacêuticas, 2017;29:264-270. DOI: 10.14450/2318-9312.v29. e3.a2017.pp264-270

29. Alves MA, Sousa AS, Silva SCS, Nogueira JRS, Martins DHN, Fonseca-Bazzo YM, Galdos-Riveros AC. Perfil fitoquímico, capacidade antioxidante e susceptibilidade antibacteriana dos extratos de Morus alba L. (Moraceae). Rev Bras. Farm, 2017;98(1):1811-1825.

30. Silva CP, Campos FA, Mendonça ED, Silva J, Ferraz A. Análise da constituição fitoquímica e antioxidante da embaúba (Cecropia pachystachya). In: XIX salão de iniciação científica e tecnológica. 2013. Canoas; 2013.

31. Souza DO, Tintino SR, Figueredo FG, Borges MCM, Braga MFBM, Felipe CFB, Da Costa JGM, Coutinho HDM, De Menezes IRA, Kerntopf MR. Atividade antibacteriana e moduladora de Cecropia pachystachya Tré- 
cul sobre a ação de aminoglicosídeos. Rev Cubana Plant Med, 2014;19(3): 121-132.

32. Zuanazzi JAS, Montanha JA. Flavonoides. In: Simões CMO, Schenkel EP, Gosmann G, Mello JCP, Mentz LAl, Petrovick PR. Farmacognosia: da planta ao medicamento. $6^{a}$ ed. Porto Alegre/Florianópolis: editora da UFSC. 2010. p.576-614

33. Gutkind G, Norbedo C, Mollerach M, Ferraro G, De Torres R. Antibacterial activity of Achyrocline flaccida. J. Ethnopharmacol, 1984;10: 319-321. DOI: 10.1016/03788741(84)90019-9.

34. Beil W, Birkholz C, Sewing KFR. Effects of flavonoids on parietal cell acid cecretion, gastric mucosal prostaglandin production and Helicobacter pylori growth. Arzneim. Forsch, 1995;45:697-699.

35. Dufresne CJ, Farnworth ER. A review of latest research findings on health promotion properties of tea. $\mathrm{J} \mathrm{Nu}$ trit Biochem, 2001;12:404-421. DOI: 10.1016/S09552863(01)00155-3.

36. De Bruyne T, Pieters L, Deelstra H, Vlietinck AJ. Condensed vegetable tannins: biodiversity in structure and biological activities. Biochem Syst Ecol 1999;27:445459. DOI: 10.1016/S0305-1978(98)00101-X.

37. Haslam E. Natural polyphenols (vegetable tannins) as drugs and medicines: possible modes of action. J Nat Prod, 1996;59:205-215. DOI: 10.1021/np960040+.

38. Scalbert A. Antimicrobial properties of tannins. Phytochemistry, 1991;30:3875-83. DOI: 10.1016/00319422(91)83426-L.

39. Waage SK, Hedin PA, Grimley E. A biologically active procyanidin from Machaerium floribundum. Phytochemistry, 1984;23:2785-2787. DOI: 10.1016/00319422(84)83016-2.

40. Taguri T, Tanaka T, Kouno I. Antimicrobial activity of 10 different plant polyphenols against bacteria causing food-borne disease. Biol. Pham Bull, 2004;27(12):19651969. DOI:1248/bpb.27.1965.

41. Paula CC. Avaliação da atividade antimicrobiana in vitro e in vivo de Conysa bonariensis (L.) Cronquist (Margaridinha do Campo) e Macrosiphonia velame (A. St.-Hil.) Müli. Arg. (Velame Branco). [Dissertação]. Cuiabá: Universidade Federal de Mato Grosso. 2010.

42. Sousa SA, Alves MA, Silva SCS, Nogueira JRS, Martins DHN, Fonseca-Bazzo YM, Galdos-Riveros AC. Phytochemical screening assessment, antioxidante capacity and antimicrobial susceptibility of extracts from $\mathrm{Ce}$ cropia pachystachya Trécul. Cecropiaceae (Urticaceae) as source for herbal medicines development. Intern J Pharmacognosy, 2015;2(12):570-576. DOI: 10.13040/ IJPSR.0975-8232.IJP.2(12).570-76.

43. Coutinho HDM, Costa JGM, Lima OE, Falcão-Silva VS, Junior-Siqueira JP. In vitro interference of Momordica charantia in the resistance to aminoglyco- sides. Pharm Biol., 2009;47(11):1056-1059. DOI: 10.3109/13880200902991540.

44. Ventura PAO, Jesus JPO, Souza Nogueira JR, Galdos-Riveros AC. Análise fitoquímica e avaliação da susceptibilidade antimicrobiana de diferentes tipos de extratos de Plantago major L. (Plantaginaceae). Infarma - Ciências Farmacêuticas, 2016;28 (1): 33-39. DOI: 10.14450/23189312.v28.e1.a2016.pp33-39.

45. Schofield P, Mbugua DM, Pell AN. Analysis of condensed tannins: a review. Animal Feed Sci Technol. 2001;91(12):21-40. DOI: 10.1016/S0377-8401(01)00228-0.

46. Ikigai H, Nakae T, Hara Y, Shimamura T. Bactericidal catechins damage the lipid bilayer. Biochem Biophys Acta. 1993;1147(1):132-136. DOI: 10.1016/00052736(93)90323-R.

47. Scazzocchio F, D'auria FD, Alessandrini D, Pantanella F. Multifactorial aspectis of antimicrobial activity of propolis. Microbiol Res. 2006;161(4):327-333. DOI: 10.1016/j.micres.2005.12.003.

48. Plaper A, Golob M, Hafner I, Oblak M, Solmajr T, Jerala R. Characterization of quercetin binding site on DNA gyrase. Biochem Biophys Res Commun. 2003;306(2):530536. DOI: 10.1016/S0006-291X(03)01006-4.

49. Kutchan TM. Plant physiology. v. 125. 2001.

50. Gobbo-Neto L, Lopes NP. Plantas medicinais: fatores de influência no conteúdo de metabólitos secundários. Quim. Nova, 2007;30(2):374-381.

51. Jalal MAF, Read DJ, Haslam E. Phenolic composition and its seasonal variation in Calluna vulgaris. Phytochemistry, 1982;21(6):1397-1401. DOI: 10.1016/00319422(82)80150-7.

52. Salminen JP, Ossipov V, Haukioja E, Pihlaja K. Seasonal variation in the content of hydrolysable tannins in leaves of Betula pubescens. Phytochemistry, 2001;57(1):15-22. DOI: 10.1016/S0031-9422(00)00502-1.

53. Feeny PP, Bostock H. Seasonal changes in the tannin content of oak leaves. Phytochemistry, 1968;7(5):871880. DOI: 10.1016/S0031-9422(00)84845-1.

54. Cooper-Driver G, Finch S, Swain T, Bernays E. Seasonal variation in secondary plant compounds in relation to the palatability of Pteridium aquilinum. Biochem Syst Ecol, 1977;5(3):177-183. DOI: 10.1016/0305-1978(77)900023.

55. Dustin CD, Cooper-Driver GA. Changes in phenolic production in the hay-scented fern (Dennstaedtia punctilobula) in relation to resource availability. Biochem Syst Ecol, 1992;20(2):99-106. DOI: 10.1016/03051978(92)90096-V.

56. Evans WC. Trease and Evans Pharmacognosy. 14 ed. WB Saunders Company: London, 1996.

57. Waterman PG, Mole S. Analysis of phenolic plant metabolites. 1 ed. Blackwell Scientific Publications: Oxford, 1994. 